\title{
Autosomal recessive mendelian susceptibility to mycobacterial diseases due to partial IFNgammaR1 deficiency
}

INSERM

\section{Source}

INSERM. (1999). Orphanet: an online rare disease and orphan drug data base. Autosomal recessive mendelian susceptibility to mycobacterial diseases due to partial IFNgammaR1 deficiency. ORPHA:319569

Autosomal recessive (AR) mendelian susceptibility to mycobacterial diseases (MSMD) due to partial IFN-gammaR1 deficiency is a genetic variant of MSMD (see this term) characterized by a partial deficiency in IFN-gammaR1, leading to a residual response to IFN-gamma and, consequently, to recurrent, moderately severe infections with bacillus Calmette-Guérin (BCG) and other environmental mycobacteria (EM). 